\title{
SLICING COLORS, ENGANANDO A VISÃO
}

Felipe Machado- UNESC

A tatuagem é uma das mais antigas formas de expressão artística, com indícios de pessoas tatuadas a mais de 5.300 anos. Essa afirmação foi apresentada para o mundo após o descongelamento de uma galeria nos Alpes Suíços no ano de 1990, quando cientistas acabaram descobrindo uma múmia que estava praticamente intacta por ter sido preservada em decorrência das baixas temperaturas. A múmia foi encontrada na região de Otzila e para homenagear o local de sua descoberta, batizaram-na de Otzil. Essa múmia possuía mais de 60 marcas espalhadas pelo corpo de forma ordenada, deixando claro que essas perfurações não foram feitas de forma obrigatória. Mesmo assim não podemos afirmar qual o real motivo que levou Otzil a fazer suas tatuagens, seja por motivos religiosos, festivos, estéticos ou até mesmo para caçar. A grande verdade é que esses são os maiores motivos que levaram os povos indígenas a se perfurarem e marcarem suas peles para se tornar diferente dentro do contexto onde viviam e muitos estudiosos afirmam que a tatuagem tenha surgido após algum ferimento de luta corporal ou até mesmo com espinhos das plantas e os desenhos que eram feitos superficialmente, para distinguir cada membro da tribo, acabavam escorrendo após a chuva ou um banho, permaneceram na pele após esse ferimento cicatrizar.

A prática se difundiu por todo mundo e os motivos eram variados: desde rituais religiosos, marcação de prisioneiros e escravos, ornamentação, identificação de grupos sociais e até mesmo camuflagem. No ocidente essa prática caiu em desuso com a perseguição da igreja católica aos tatuados, se baseando no livro de Levítico do antigo testamento, onde ela afirmava ser pecado a incisão de tinta na pele e a perfuração da mesma por estar relacionado a um ferimento desnecessário.

Somente em 1769 a prática ressurgiu para a sociedade, após uma viagem feita pelo navegador inglês James Cook à Polinésia, que registrou no seu diário de bordo uma experiência vivenciada nessa sua expedição. Ele escreveu: "Homens e mulheres pintam seus corpos. Na língua deles, chamam isso de tataw. Injetam pigmento preto sob a pele de tal modo que o traço se torna indelével". 
Ele ficou tão impressionado com essa experiência que ao voltar para a Inglaterra acabou apresentando para as pessoas de seu convívio a prática e tornou ela popular novamente. Como o nome era no dialeto dos indígenas, só se mencionava a onomatopeia que formava após o toque das madeiras e ossos que eram utilizados para inserir a tinta na pele. Então o mesmo "tataw" que era mencionado pelos povos ancestrais agora passaria a ser chamado de "tattoo". A origem da palavra britânico, que está ligada aos ingleses é "terra de pessoas pintadas" devido ao grande número de pessoas que aderiram a essa prática após esse ressurgimento definitivo. A popularidade da tatuagem se tornou tão expressiva, que cem anos após Cook traze-la de volta para a sociedade, Charles Darwin afirmaria que nenhuma nação desconhecia a tatuagem. A grande verdade é que em cada canto do mundo, alguém já fez ou ouviu falar da tatuagem deixando bem claro sua popularidade e aceitação.

Foi em 1981 que aconteceu algo primordial para essa arte se tornar ainda mais expressiva, nesse ano foi inventada a máquina elétrica, tornando assim, mais fácil a aplicação da tinta na pele. Esse acontecimento foi muito importante na cronologia da prática da tatuagem, pois foi a partir desse momento que ela deixou de ser de uso exclusivo dos marinheiros e presidiários.

Com o passar dos anos tudo que está relacionado à tatuagem teve uma grande evolução. E assim como outras vertentes da arte ela também foi crescendo e sendo valorizada com o passar dos tempos, assim como as tintas e os pinceis foram sendo desenvolvidos na pintura, desde qualidade até maneira como embalar, os materiais de tatuagem também vem recebendo uma atenção mais redobrada. As tintas que no início eram extraídas de raízes das plantas e sementes esmagadas passaram a ser produzidas a partir de minerais e hoje são feitas com produtos orgânicos. As agulhas produzidas com ossos e espinhos de plantas passam agora por um rigoroso padrão de qualidade para que penetrem na pele com a maior suavidade possível, causando assim o mínimo de lesão para um trabalho final com maior qualidade, bem como todos os produtos que são utilizados durante uma sessão de tatuagem. Os órgãos de vigilância sanitária de cada país são responsáveis pela fiscalização dos materias que são utilizados pelos tatuadores em seus procedimentos, mantendo assim um nível de segurança altíssimo em relação aos riscos que a prática trás quando se fala de doenças infecciosas.

Essa modernização chegou também para os desenhos desenvolvidos para tatuagem, e o que antigamente era feito simplesmente para ornamentar o corpo, hoje 
se tornou muito mais significativo e pessoal. Atualmente as pessoas buscam uma tatuagem para marcar um momento da vida, o nascimento de um filho, se identificar dentro de um grupo, para expressar seus gostos e suas conquistas. Os desenhos feitos no passado já não representam mais as mesmas coisas e provavelmente se tornaram ultrapassados na maioria dos casos, bem como as tradicionais tatuagens com nome de namorados, que com o fim do relacionamento só resta a remoção a laser ou a cobertura com uma tatuagem mais moderna e significativa.

Provavelmente, uma tatuagem que era bonita há dez anos, já não causa a mesma impressão em quem a observa. Esses são alguns dos motivos que leva uma pessoa a buscar a remoção ou cobertura da tatuagem. Surge então um grande problema, pois o laser que é utilizado para remoção da tatuagem pode lesionar um melanoma, que é uma célula de um possível câncer de pele que está adormecido, trazendo consigo um problema bem maior que uma simples tatuagem indesejada lhe proporcionava. A segunda opção seria uma cobertura, possibilitando ao cliente a escolha de um desenho mais atual e relevante para si. O grande problema dessa prática mencionada é que muitos profissionais se limitam a fazer tatuagens escuras para uma cobertura mais confortável para eles, e muitas vezes o próprio cliente trás um desenho escuro, imaginando que essa é a melhor opção para esconder uma tatuagem antiga.

Isso não deixa de ser verdade, pois a cor escura na tatuagem sempre vai se sobressair em relação a uma cor clara, facilitando assim o trabalho do tatuador nesse trabalho em especial. Porém, após a tatuagem terminada e cicatrizada, ela dá uma impressão de que algo está errado, pois geralmente se coloca cores escuras onde deveriam conter cores claras, dando certo desconforto visual ao observador. Trazendo por sua vez a necessidade de descobrir o porquê de uma cor indevida em um ponto inesperado. Chegando até a necessidade de o observador perguntar ao tatuado qual o motivo daquela cor em ou detalhe escuro, muitas vezes até com sombreado em um ponto inesperado, fazendo com que o tatuado acabe dizendo que a tatuagem atual trata-se de uma cobertura. Trazendo assim a lembrança que o tatuado já não queria mais carregar consigo.

Assim como diversos profissionais, considerados os grandes mestres da body art no Brasil, podemos citar Snoop e Andre Meyer, já cometeram erros gravíssimos nas perfurações, também errei gravemente nas coberturas.

Durante meus 19 anos de carreira, estive permanentemente em contato com o que havia de mais moderno em matéria de body-piercing. Conhecimento que adquiri por meio de convenções, workshops e palestras. Ao mesmo tempo, me preocupei em passar este conhecimento adiante, dando cursos mensais, onde se formaram milhares de profissionais que vêm colaborando 
para tornar a colocação de piercings uma prática segura e sedimentada no Brasil. (Meyer, 2011, p.195)

Porém, assim como eles, também me aprofundei no assunto, adquiri conhecimentos, participei de palestras, e fui conhecendo o corpo, a pele, as tintas cada vez mais a fundo. No início o cliente sempre optava nas cores e desenhos, e eu tentava fazer a melhor cobertura possível de acordo com o desejo dele, dessa forma acabei descobrindo que algumas cores não desempenhavam esse papel e aos poucos fui me adaptando e ajudando o cliente na escolha das cores, sempre mencionando experiências já vivenciadas com outros clientes.

Foi trabalhando dessa forma que senti a necessidade de desenvolver uma técnica que permitisse uma cobertura mais discreta e concisa em relação às conhecidas até então. Após vários anos trabalhando com tatuagem, percebi quais cores, mesmo sendo claras, poderiam ser usadas para cobertura de uma tatuagem. Muitas vezes até a consistência da tinta proporcionava um resultado diferenciado, fazendo com que eu deixasse separadas algumas cores em seus recipientes como se fossem secar para que elas ficassem mais pastosas e me permitisse realizar esse trabalho com mais segurança.

Desenvolvi o que chamo de "slicing colors", que agregado a esses pequenos detalhes que mudam a característica da tinta, me permite oferecer ao cliente uma cobertura com cores claras, o que muitas vezes é desconhecido por ele fazendo com que ele se sinta desestimulado em procurar esse serviço devido a falta de profissionais que the ofereçam essa possibilidade. $E$ isso acontece pelo simples fato de que é muito mais conveniente ao tatuador negar esse serviço ao cliente dizendo que nenhuma técnica vai garantir esse resultado e oferecer ao cliente uma nova tatuagem em local novo e podendo cobrar o mesmo preço por um serviço mais simples e sem tantos riscos como é uma cobertura. Embora seja a opção mais viável para o tatuador, acredito que o cliente deve ser correspondido nessa sua necessidade, e foi isso que me motivou a desenvolver a técnica apresentada. Ao longo dos anos fui acompanhando cada cliente e cada processo de cicatrização para que após um trabalho finalizado e cicatrizado pudesse ter a certeza do sucesso de tal procedimento.

A cobertura pelo slicing colors se dá com resultado mais satisfatório quando aliada a um desenho adequado para a mesma. Caracterizar a variação de 
cores e tons são muito bem-vindas para que a visão seja confundida, e dessa forma a tatuagem de cobertura deixe bem abstruso o desenho antigo. Quando colocamos de forma repetida e sistemática as cores em um determinado desenho, ele consegue embaralhar a visão fazendo com que ela fique mais confortável vendo a tatuagem nova do que quando procuramos por um desenho que está escondido. Desta forma o Slicing Colors se adequa bem a qualquer tipo de cobertura, pois vai executar bem o papel de esconder a tatuagem antiga e ainda assim continuar com total discrição para que não fique explicito de que se trata de uma cobertura.

A maneira com a qual ela é desenvolvida e executada, fazendo uso de cores claras e com grande gama de tonalidades, é que faz com que esse estilo alcance o nível desejado. O intuito já não é somente esconder uma tatuagem, mas sim fazer com que o observador não estranhe uma cor de tonalidade mais escura em um ponto onde deveria ser exatamente o contrário. Após ver esse trabalho ele deve ter uma sensação de satisfação sem ter o desejo de descobrir o que tinha por baixo, ao visualizar qualquer traço ou cor do trabalho antigo.

Nessa mesma linha de pensamento Didi-Huberman, Georges afirma:

[...] Ele pretenderá eliminar toda construção temporal fictícia, quererá permanecer no tempo presente de sua experiência do visível. Pretenderá eliminar toda imagem, mesmo "pura", quererá permanecer no que vê, absolutamente, especificamente. Pretenderá diante $\mathrm{Da}$ tumba não rejeitar a materialidade do espaço real que se oferece a sua visão quererá não ver outra coisa além do que vê presentemente."

Isso significa que é mais conveniente para os olhos ficar atento ao que está mais fácil de ser percebido ou entendido. Uma vez que ele observa certo desenho e dá significado ao mesmo, é mais cômodo aceitar o que está diante de seus olhos do que procurar um segundo desenho.

Após vários testes, cheguei à conclusão que se eu enganasse a visão do observador eu teria um resultado quase que perfeito. Então procurei criar uma espécie de llusão de ótica, termo usado a todas ilusões que "enganam" o sistema visual humano, fazendo-nos ver qualquer coisa que não está presente ou fazendo-nos vê-la de outro modo. As ilusões de óticas podem ser de carácter fisiológico e outras de carácter cognitivo, envolvendo assim, fatores diversos como o pensamento, a percepção, a memória, o raciocínio etc., que fazem parte do desenvolvimento intelectual. No processo de desenvolvimento do slicing colors, 
acabei percebendo que muitas vezes não era necessário esconder por completa a tatuagem anterior, podendo assim ficar aparecendo um traço ou uma cor do antigo desenho desde que a tatuagem nova trouxesse uma informação relevante ou agradável aos olhos do observador, fazendo com que o foco do seu olhar fique direcionado no local previamente designado pelo artista que executou o desenho e a tatuagem.

Nossa visão é um sentido muito falho e debilitado, podendo ser enganado facilmente. Basta proporcionar algo mais confortável ou que chame mais atenção dos olhos e o trabalho alcançará um nível de satisfação desejado.

\begin{abstract}
Pesquisas sobre ilusões de ótica ressaltam um ponto principal: que nosso sistema visual é muito limitado para processar com precisão todas as informações que nossos olhos absorvem, portanto, ele funciona com base na interpretação mais provável. Em raras ocasiões, o cérebro faz uma interpretação errada, fazendo com que percebamos algo de forma imprecisa: uma ilusão de ótica. Em outras ocasiões, pessoas diferentes podem perceber as coisas de formas diferentes. Na verdade, se você já se esforçou para ver uma imagem "escondida" em um estereograma de imagem única, ou discutiu com um amigo sobre a cor de um vestido, você provavelmente observou que nem todos experimentam as ilusões visuais da mesma forma. (Wikipédia,2016)
\end{abstract}

$\mathrm{Na}$ grande maioria das vezes nossa visão assimila apenas aquilo que é mais provável e de fácil percepção, pois o observador quer aproveitar ao máximo o momento de informação que a imagem lhe proporciona e também pelo fato de exigir certa destreza da parte do observador para que o mesmo consiga encontrar uma mensagem que tenha sido escondida propositalmente. Levando em consideração que nosso sistema visual e muito limitado para processar com precisão o que nossos olhos observam para ele e mais cômodo enxergar sem esforço, ou seja, apenas aquilo que esta a sua frente e lhe e agradável.

Quando um cliente procura um tatuador para fazer a cobertura ele deve estar preparado que sua nova tatuagem obedeça alguns critérios para que o resultado final Ihe traga a satisfação desejada. Características básicas como tamanho, linhas e cores são muito bem estudadas para que o desenho continue sendo harmonioso e que possibilite um trabalho mais adequado de acordo com o nível de dificuldade apresentado e até mesmo em relação a cor da pele da pessoa.

O tamanho do desenho deve ser sempre maior do que a tatuagem antiga para que não fique amostra nenhum traço, cor ou sombra, deixando a entender que 
se trata de uma cobertura. Se necessário o tatuador pode fazer pequenos ajustes para que esses elementos não sejam percebidos. No caso de flores, as folhas que acompanham o desenho podem ser colocadas nesses pontos que se fazem necessário, nas tatuagens orientais, as águas são sempre bem vindas e significativas, podendo ser incluídas também. Ornamentos vetoriais para mulheres ou um sombreado chapado para homens acabam suprindo essa deficiência.

Quando colocadas paralelamente, as linhas acabam chamando uma atenção superior quando comparadas as linhas mais afastadas ou que não seguem o mesmo padrão. E no slincig colors essa possibilidade faz com que uma sequencia de linhas se sobressaiam a tatuagem antiga. Muitas vezes o próprio decalque (ato de aplicação do desenho que antecede o procedimento da tatuagem) já apresenta essa quantidade maior de linhas, e ele por si só já consegue esconder a tatuagem antiga sem mesmo ter se iniciado a incisão da tinta sob a pele.

A variação de cores talvez seja a maior aliada dessa técnica, pois assim como a sequencia de linhas apresenta esse característica de ocultar uma tatuagem antiga, e também proporciona ao profissional essa alternativa de trocar o foco da visão. Um ótimo exemplo são as tatuagens do estilo oriental, que representam na maioria animais mitológicos ou não, com uma característica muito peculiar que são as escamas. Pode ser um dragão, uma fênix, uma carpa, que são os mais procurados pelos clientes, mas o fato é que por apresentar na maioria dos casos escamas em sua composição esses desenhos permitem uma troca de cor frequente em cada variação de escama, sendo muito bem aceito para esse tipo de cobertura. Em um dragão com base azul, por exemplo, cada escama pode apresentar pelo menos quatro cores. Ela começaria com o branco na sua borda para dar suavidade e delimitar o elemento, seguido por um azul claro, também chamado de celeste, tendo em seguida o azul médio, ou azul mar, e terminando com um tom mais escuro de azul fazendo o papel de sombra e profundidade da escama. Essa troca de cores em um pedaço tão pequeno da tatuagem e que se repete por ela consequentemente, faz com que não tenhamos a possibilidade de procurar por algo subliminar. Seria muito cansativo para nossa visão procurar por algo escondido além de interpretar essa variação de cores ou tonalidades aplicadas no processo de criação e finalização do desenho e tatuagem. 
Quanto mais escura for a tatuagem antiga, maior será a necessidade de mescla de cores e tons, e nesse caso é muito bem aceito um desenho que apresente linhas paralelas em demasia, pois essa característica dentro do desenho permite uma abrangência maior de cores proporcionando uma ilusão de ótica ao observador. As linhas não necessitam de uma proximidade tão grande desde que possibilitem essa troca de cores citadas acima.

Desta forma o Slicing Colors se adequa bem a qualquer tipo de cobertura, pois vai executar bem o papel de esconder a tatuagem antiga e ainda assim continuar com total discrição para que não fique explicito de que se trata de uma cobertura.

A maneira com a qual ela é desenvolvida e executada, fazendo uso de cores claras e com grande gama de tonalidades, é que faz com que esse estilo alcance o nível desejado. O intuito já não é somente esconder uma tatuagem, mas sim fazer com que o observador não estranhe uma cor de tonalidade mais escura em um ponto onde deveria ser exatamente o contrário. Após ver esse trabalho ele deve ter uma sensação de satisfação sem ter o desejo de descobrir o que tinha por baixo ao visualizar qualquer traço ou cor do trabalho antigo.

Fica claro que este estilo de cobertura desempenha muito bem seu papel que é de ocultar uma imagem antiga ou que atualmente seja indesejada. Existem diversas práticas e técnicas que possibilitem uma cobertura, como já citado anteriormente, mas nem sempre o cliente está disposto a correr o risco que o laser trás consigo, ou não está querendo uma tatuagem escura com o preto predominando o desenho. Não podemos descartar essas possibilidades, até mesmo porque muitos clientes procuram tatuagens feitas nos estilos tribais e tribais maori para uma cobertura, e essas são em sua imensa maioria de base preta com pouquíssima cor complementando o desenho em alguns casos específicos. Mas o profissional que vai executar o serviço deve estar preparado para suprir esse anseio de cobertura com um desenho colorido que muitas vezes acompanham o cliente.

O tatuador deve se manter em constante busca de conhecimento, tanto na área artística quanto na parte de biossegurança. Acompanhar essa busca pelo novo, pelo que vai realmente lhe proporcionar prazer e satisfação sem deixar de lado a parte de higiene e normas de saúde que essa arte exige, dando assim total segurança 
ao seu cliente. Vários são os motivos que levam uma pessoa a procurar um profissional que faça tal trabalho.

\begin{abstract}
A tatuagem, assim praticada, assume o papel de um texto que preserva a memória do ritual - contexto - em que é concebida. O deu importa é tatuarse, marcar no espaço do corpo a época, o acontecimento, a memória ou simplesmente fazer parte do grupo tatuado. A partir disso, qualquer imagem, ou toda imagem, adquire uma aura para seu portador. (RAMOS, p.173)
\end{abstract}

Perdeu-se muito o motivo clássico por ser fazer tatuagem, e o que antes era feito para representar uma atitude ou uma ideologia, é feito simplesmente para ornamentar o corpo. Talvez seja esse o maio motivo que leva as pessoas a se arrependerem de suas tatuagens.

Porém o tatuador que executa bem qualquer tipo de técnica, não pode tornar seu cliente um refém de seu trabalho simplesmente pela qualidade plástica oferecida. Essa busca de novas técnicas pode ser feita dentro de seu próprio Studio tendo a participação ativa de seus próprios clientes. Uma técnica apurada leva algum tempo para ser desenvolvida, e a processo muitas vezes é cansativo e pouco lucrativo. Não são todos profissionais que executam esse serviço com a técnica correta, muitas vezes não possuírem destreza nesse tipo de trabalho, por não praticarem e muitas vezes até desestimular o cliente em cobrir sua tatuagem.

Não é nem um pouco equivocado dizer que uma cobertura exige um pouco mais de atenção. Seja no momento da escolha do desenho, do tamanho e das cores a serem utilizadas. Por esse motivo tantos tatuadores preferem dizer que não é possível cobrir ou então cobrar um preço elevado para que o cliente desista de fazer a cobertura e opte por uma nova tatuagem em outro local do corpo, pois desconhecem essa técnica de cobertura ou simplesmente não praticam nem desenvolveram um modo no qual proporcione a eles um resultado satisfatório.

\title{
REFERÊNCIAS
}

MEYER, André. Lindo de doer. São Paulo: Gaia, 2011. 216 p.

DIDI-HUNBERMAN, Gerges. O que vemos, o que nos olha. 2 ed. São Paulo: 34, 2010. 264 p. 
RAMOS, Célia Maria Antonacci. Teorias da tatuagem. Florianópolis: UDESC, 2001. $204 \mathrm{p}$. 